\title{
Paediatricians' perspectives on global health priorities for newborn care in a developing country: a national survey from Nigeria
}

Bolajoko O Olusanya ${ }^{1 *}$, Chinyere V Ezeaka ${ }^{2}$, Ekundayo K Ajayi-Obe ${ }^{3}$, Mariya Mukhtar-Yola ${ }^{4}$ and Gabriel E Ofovwe ${ }^{5}$

\begin{abstract}
Background: An understanding of the perception of paediatricians as key stakeholders in child healthcare delivery and the degree of congruence with current investment priorities is crucial in accelerating progress towards the attainment of global targets for child survival and overall health in developing countries. This study therefore elicited the views of paediatricians on current global priorities for newborn health in Nigeria as possible guide for policy makers.
\end{abstract}

Methods: Paediatric consultants and residents in the country were surveyed nationally between February and March 2011 using a questionnaire requiring the ranking of nine prominent and other neonatal conditions based separately on hospital admissions, mortality, morbidity and disability as well as based on all health indices in order of importance or disease burden. Responses were analysed with Friedman test and differences between subgroups of respondents with Mann-Whitney $U$ test.

Results: Valid responses were received from 152 (65.8\%) of 231 eligible physicians. Preterm birth/low birthweight ranked highest by all measures except for birth asphyxia which ranked highest for disability. Neonatal jaundice ranked next to sepsis by all measures except for disability and above tetanus except mortality. Preterm birth/low birthweight, birth asphyxia, sepsis, jaundice and meningitis ranked highest by composite measures while jaundice had comparable rating with sepsis. Birth trauma was most frequently cited under other unspecified conditions. There were no significant differences in ranking between consultants and residents except for birth asphyxia in relation to hospital admissions and morbidity as well as sepsis and tetanus in relation to mortality.

Conclusions: Current global priorities for neonatal survival in Nigeria largely accord with paediatricians' views except for neonatal jaundice which is commonly subsumed under "other" or "miscellaneous" neonatal conditions. While the importance of these priority conditions extends beyond mortality thus suggesting the need for a broader conceptualisation of newborn health to reflect the current realities, paediatricians should be actively engaged in advancing the attainment of global priorities for child survival and health in this population.

Keywords: Newborn health, Global health, Developing country, Health priorities

\footnotetext{
*Correspondence: boolusanya@aol.com

${ }^{1}$ Healthy Start Initiative, Ikoyi, Lagos, Nigeria

Full list of author information is available at the end of the article
} 


\section{Background}

Despite declining under-5 mortality rates worldwide, recent global estimates still suggest that about 8.8 million children die every year out of which $41 \%$ (about $3.6 \mathrm{mil}-$ lion deaths) occur in the neonatal period compared with $37 \%$ a decade ago [1]. Similarly, while neonatal mortality in Nigeria declined from 53 to 39 per 1000 live births in the last decade, the country still accounts for $8.3 \%$ of global neonatal deaths (behind India and China). Based on the annual rate of change from 1990 to 2011, Nigeria is one of the 23 countries in sub-Saharan Africa that are unlikely before 2040 to achieve the Millennium Development Goal (MDG) 4 of reducing the under-5 mortality rate by two-thirds between 1990 and 2015 [2]. Complications of preterm birth, birth asphyxia, infections, diarrhoea, tetanus and congenital abnormalities have been extensively reported as the leading causes of neonatal deaths for which priority investment is urgently required to build requisite national capacity to effectively address these conditions [1].

Besides the prevailing concerns about the slow pace of progress on mortality reduction in some developing countries, morbidity and disability are gaining recognition also as important indices of newborn health especially within the context of the expanding populations of child survivors $[3,4]$. For example, preterm birth, birth asphyxia and congenital abnormalities are not only the leading causes of mortality but also associated with significant morbidity and long-term sequelae in survivors $[5,6]$. However, the relative importance and contributions of these conditions to neonatal hospitalisation, morbidity and disability remain unknown and thus difficult to prioritise due to lack of population-based data. Survey of physicians has always served as a valuable tool and cost-effective source of information in health services and policy research worldwide especially in resource-limited settings [7]. The critical role of physicians in influencing individual and community healthseeking behaviour is also widely acknowledged thus making them valuable partners in public health promotion. Additionally, it is more likely that paediatricians would demonstrate a higher level of commitment to policy initiatives that reflect the views of the majority and respected colleagues in comparable circumstances as far as practicable [8]. This study therefore set out to establish the views of paediatricians on priorities for newborn survival and health and the relationship with current global health priorities in Nigeria.

\section{Methods}

We surveyed paediatric consultants and residents on the electronic mailing list of the Paediatric Association of Nigeria (PAN) as at $31^{\text {st }}$ December 2010. Four of the authors verified the list of eligible recipients as the PAN mailing list also included non-paediatricians that had attended its past conferences. Respondents were requested to complete either an online version (Survey Monkey; Palo Alto, CA, USA) or a one-page MS Word version of a questionnaire (Additional file 1). The questionnaire was pretested for clarity, comprehension and completion time among eight paediatricians in different public and private hospital settings in Nigeria as well as one US-based neonatologist with extensive experience with the local practice since 1994. The first invitation was made in February, 2011 and continued till end of March 2011. The study rationale was communicated in a covering letter and this was followed with repeated appeals for participation. Those who were missed during the first invitation as identified by the authors were further contacted prior to the analysis of the data. No financial incentives were offered to prospective respondents. As this study was essentially an audit of professional opinion and no definite data on human subjects was solicited, formal institutional approval as stipulated by the Helsinki Declaration was not considered mandatory.

Basic demographic and work-related personal profile was requested from each respondent. This included sex, age, years in practice since primary medical qualification and membership status with PAN. Respondents were also required to state their position/status in current, most recent or last appointment (Professor, Lecturer, Consultant, Resident or Medical Officer), the type of practice setting (Tertiary, General or Secondary, Health Centre, Other) and type of employer (Government or Private Ownership, Non-Governmental Organisation, International Organisation or Other). Each respondent was then required to rank nine specific neonatal conditions in order of importance or disease burden based on their contributions to four key health outcomes. The selected conditions were preterm birth/low birth weight, birth asphyxia, sepsis, pneumonia and meningitis, diarrhoea, tetanus, jaundice and congenital abnormalities based on the International Classification of Diseases, $10^{\text {th }}$ revision $(\mathrm{ICD}-10)$ and relevant literature $[1,3]$. A tenth category was created for other unspecified conditions. Jaundice, usually subsumed under "other neonatal conditions" was identified separately because of available regional/local evidence on its contribution to all four outcomes: hospital admissions for special care, mortality, morbidity and disability [5,9-15]. We hypothesised that the practitioners' overall priorities will be reflected in the pattern of allocating financial resources among the various conditions with a given budget. Respondents were therefore requested to indicate how they would allocate a hypothetical grant of US\$100,000 across these conditions as a measure of the composite priority across the four main outcomes. 


\section{Statistical analysis}

The responses were analysed using IBM SPSS Statistics (Version 20). The individual rankings were rated in reverse order with the most preferred rated as 10 . The mean ranks for the 10 conditions across the four outcomes and the financial allocation by respondents were determined with Friedman non-parametric test as no assumptions were made on the underlying distribution of the data. Perceived differences between specific groups of respondents for each of the health measures were explored with a two-tailed Mann-Whitney $U$ test. Statistical significance was assessed at critical level of $\mathrm{p}<0.05$.

\section{Results}

A total of 73 online and 94 paper responses were received. Two online duplicates, one invalid online response, five paper duplicates of online responses and seven ineligible paper responses from medical or house officers were excluded. A total of 152 valid responses representing $65.8 \%$ of the 231 eligible respondents from our mailing list were analysed. The respondents were 15 professors, 77 consultants and 60 residents spread over half (22) of the 36 States and Federal Capital Territory (Table 1). Overall, responses were received from 17 $(85.0 \%)$ of the 20 States with hospitals accredited for postgraduate training in paediatrics.

Summary rating scores by participants showing the descriptive statistics are presented in Table 2. The Friedman tests showed statistically significant differences in the median scores across all neonatal conditions for hospital admissions ( $p<0.001)$, mortality ( $p<0.001)$, morbidity $(\mathrm{p}<0.001)$ and disability $(\mathrm{p}<0.001)$. Post-hoc tests of significance for pair-wise comparison of all ten conditions for each of the five health outcomes were not explored as these were not considered critical to the overall objective of the study and in view of the sheer number of possible combinations.

A graphical presentation comparing the mean rank scores for all conditions across the four health indices is shown in Figure 1. Except for disability, preterm birth/ low birth weight ranked highest by all measures while birth asphyxia ranked second highest but highest for disability. Sepsis ranked above jaundice on hospital admissions, mortality and morbidity, but lower for disability. Jaundice ranked next to preterm birth/low birth weight and birth asphyxia for disability; and above tetanus by all measures except mortality. Similarly, meningitis ranked above tetanus by all measures except disability while diarrhoea ranked the least of all specific conditions by all measures.

The subgroup analysis for hospital admissions showed no significant differences between professors and consultants for all neonatal conditions. However, birth asphyxia
Table 1 Characteristics of respondents $(n=152)$

\begin{tabular}{ll}
\hline Factor & Frequency \\
\hline Sex & \\
Female & $72(47.4 \%)$ \\
Male & $80(52.6 \%)$ \\
Age & \\
Median & 41 years \\
Interquartile range & $35-48$ years \\
Post-MBBS experience & \\
Median & 17.4 years \\
Interquartile range & $9-25$ years \\
Status & \\
Professor & $15(9.9 \%)$ \\
(Senior) Lecturer/Consultant & $77(50.7 \%)$ \\
Paediatric resident & $60(39.4 \%)$ \\
Practice setting & \\
Tertiary/Teaching hospital & $124(81.6 \%)$ \\
General/Secondary hospital & $22(14.5 \%)$ \\
Private clinic & $6(3.9 \%)$ \\
Employers & \\
Federal/State government & $136(89.5 \%)$ \\
Private organisation & $15(9.8 \%)$ \\
International & $1(0.7 \%)$ \\
Geographical setting & \\
North (11 States + Federal capital territory) & $109(71.7 \%)$ \\
\hline South (10 States) & \\
\hline
\end{tabular}

was ranked significantly lower by residents compared with professors $(\mathrm{p}=0.023)$ or consultants $(\mathrm{p}=0.026)$. In relation to mortality, sepsis was ranked significantly lower by residents compared with either professors $(\mathrm{p}=0.038)$ or consultants $(\mathrm{p}=0.038)$ while tetanus was ranked significantly higher compared with professors $(p=0.022)$ or consultants $(p=0.010)$. No differences were found between professors and consultants across all conditions. Based on morbidity, birth asphyxia was ranked significantly lower by residents compared with consultants $(p<0.001)$. No significant differences were observed between subgroups for all specific conditions in terms of disability and budget allocation.

The average or composite ratings across all measures compared with the priorities for investment are shown in Figure 2. As hypothesised, there was concordance between the composite ratings and investment profile. The top five priorities (mean rank $\geq 5$ ) were preterm birth/ low birth weight, birth asphyxia, sepsis, jaundice and meningitis. Jaundice ranked pari-passu with sepsis by composite rating and level of proposed investment.

Conditions typically mentioned under "others" included umbilical cord bleeding, meconium aspiration, 
Table 2 Summary of rating scores by all participants for all neonatal conditions

\begin{tabular}{|c|c|c|c|c|}
\hline \multirow[t]{2}{*}{ Conditions } & \multicolumn{4}{|c|}{ Median (Interquartile Range); Mean Rank } \\
\hline & Admissions & Mortality & Morbidity & Disability \\
\hline Prematurity/LBW & $9.0(8.0-10.0) ; 8.9$ & $9.0(8.0-10.0) ; 8.9$ & $9.0(8.0-10.0) ; 8.8$ & $8.0(7.0-9.0) ; 7.9$ \\
\hline Birth asphyxia & $9.0(7.8-9.3) ; 8.4$ & $9.0(8.0-10.0) ; 8.4$ & $9.0(8.0-10.0) ; 8.5$ & $10.0(9.0-10.0) ; 9.0$ \\
\hline Sepsis & $8.0(7.0-9.0) ; 8.3$ & $7.0(6.0-8.0) ; 6.9$ & $7.0(5.0-8.0) ; 6.9$ & $5.0(4.0-6.0) ; 5.5$ \\
\hline Meningitis & $5.0(4.0-6.0) ; 5.2$ & $6.0(5.0-7.0) ; 6.0$ & $6.0(5.0-7.0) ; 6.0$ & $7.0(6.0-8.0) ; 7.2$ \\
\hline Pneumonia & $5.0(4.0-5.3) ; 4.5$ & $4.0(3.0-6.0) ; 4.5$ & $4.0(3.0-5.0) ; 4.4$ & $4.0(3.0-4.3) ; 3.8$ \\
\hline Diarrhoea & $3.0(2.0-4.0) ; 3.3$ & $3.0(2.0-4.0) ; 3.0$ & $3.0(2.0-4.0) ; 3.1$ & $2.0(2.0-3.0) ; 2.5$ \\
\hline Tetanus & $4.0(3.0-5.0) ; 4.1$ & $7.0(4.0-8.0) ; 6.2$ & $5.0(3.0-6.0) ; 4.7$ & $4.0(2.0-6.0) ; 4.2$ \\
\hline Jaundice & $7.0(7.0-9.0) ; 7.4$ & $5.0(3.0-6.0) ; 4.9$ & $7.0(6.0-8.3) ; 6.8$ & $8.0(6.8-9.0) ; 7.6$ \\
\hline Congenital defects & $3.0(2.0-5.0) ; 3.4$ & $4.0(2.0-6.0) ; 4.6$ & $4.0(2.0-6.0) ; 4.4$ & $6.0(4.0-8.0) ; 5.9$ \\
\hline Others & $1.0(1.0-1.3) ; 1.6$ & $1.0(1.0-1.0) ; 1.6$ & $1.0(1.0-1.0) ; 1.5$ & $1.0(1.0-1.0) ; 1.5$ \\
\hline Friedman test & $p<0.001$ & $p<0.001$ & $p<0.001$ & $p<0.001$ \\
\hline
\end{tabular}

macrosomia, congenital heart disease, birth injuries traditional medications, severe anaemia, HIV and metabolic disorders. Only 39 respondents made free remarks which included "separating septicaemia with/without non-pneumonia respiratory disorder from pneumonia might be rather challenging", "neonatal sepsis and meningitis could be taken together since the usual practice is to exclude or confirm meningitis once sepsis is suspected", "we seldom see cases of neonatal tetanus" and "degree of ignorance about neonatal jaundice even among the educated is alarming".

\section{Discussion}

This survey suggests that paediatricians' views accord with various published reports that rank preterm birth/ low birth weight, birth asphyxia and sepsis as the leading causes of neonatal mortality in Nigeria $[1,16,17]$. This is reassuring as recent reports suggest that most countries in Sub-Saharan Africa are unlikely to achieve neonatal mortality rates comparable to levels currently reported in high-income countries before 2065 at the existing rate of progress [18]. Efforts to accelerate reduction in neonatal mortality rate such as promotion of delivery with skilled birth attendants, the 'helping babies breathe' global initiative for neonatal resuscitation and revision of the integrated management of childhood illness (IMCI) algorithms to improve management of neonatal infections and preterm births therefore deserve greater attention from all stakeholders at all levels of health care delivery.

However, paediatricians' views on these priority conditions are not limited to mortality and underscore the need not to overlook the full health spectrum of these conditions especially as the vast majority of infants are delivered outside hospitals. For example, the economic burden of preterm births/low birth weight survivors in

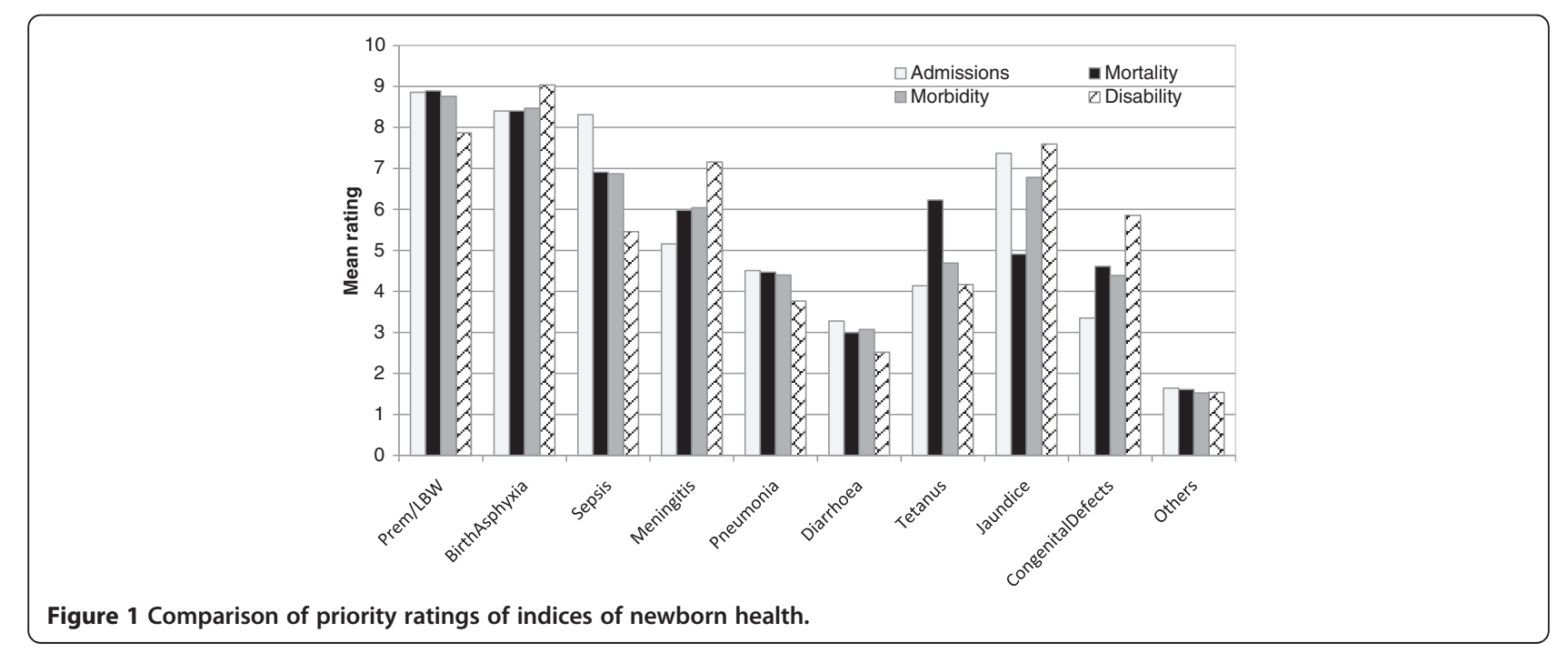




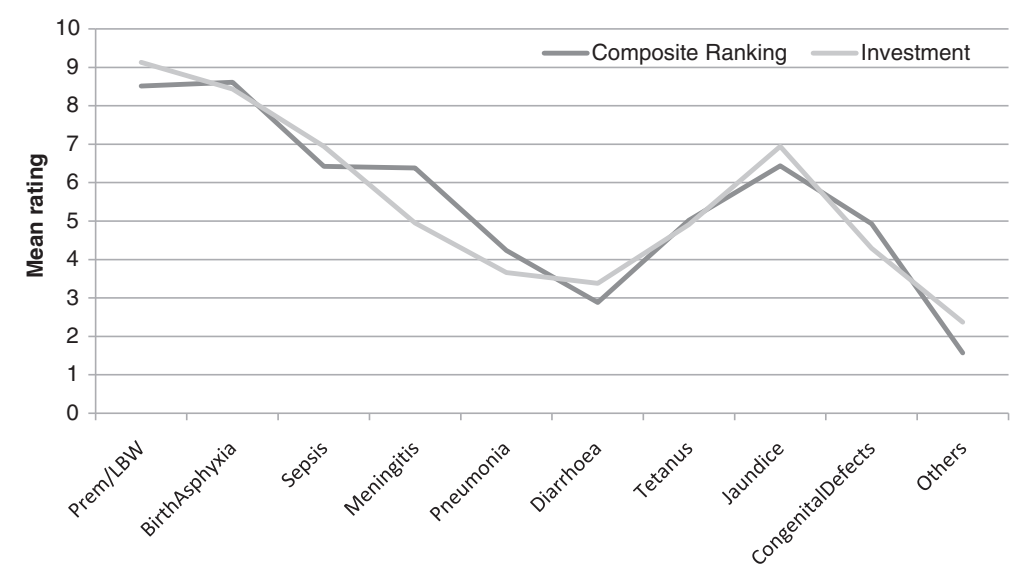

Figure 2 Comparison of priority ratings based on composite ranking all conditions and planned investment.

terms of immediate hospital care and long-term support are beyond the means of most families [19]. While the prevention of preterm births altogether remains unattainable goal worldwide, the health care system even at the tertiary level is generally ill-equipped to provide ongoing care for otherwise healthy children with special needs. An integrated approach for the management of preterm/low birth weight infants is therefore essential in effectively addressing the associated immediate and long-term burden.

Perhaps the most notable finding is the comparable overall rating for sepsis and jaundice after preterm births and birth asphyxia. Evidently, the common practice of subsuming neonatal jaundice under "other conditions" in various reports on global child health seems inappropriate for Nigeria and perhaps possibly for other countries in Africa where severe jaundice has been associated with significant morbidity and mortality [5,9,10,12,17]. Available facilities in many hospitals make it impracticable to accurately distinguish between early-onset sepsis and jaundice based on the immediate clinical signs or symptoms [20,21]. It is therefore not uncommon for infants with jaundice to be treated routinely for suspected sepsis as a first-line intervention until laboratory investigations confirm otherwise even though both conditions are more often unrelated in this setting.

The adverse consequences of severe jaundice and acute bilirubin encephalopathy are entirely preventable through effective clinical and surveillance protocol. Close and objective monitoring of bilirubin levels as well as prompt treatment with phototherapy is all that is needed by majority of the affected infants failing which exchange transfusion is warranted. However, the benefits of these treatments are - seldom available due to the lack of requisite or functional facilities. Early hospital discharge within 48 hours of birth or delivery outside hospital often results in late presentation in hospitals. This delay is often exacerbated by poor recognition of jaundice especially by first-time mothers and the common recourse to traditional herbal therapies before seeking medical attention [22]. Even in hospitals with phototherapy units, lack of routine maintenance and evaluation of the irradiance levels often results in high rates of exchange transfusions $[11,23]$. The only community-based data on severe neonatal jaundice in Nigeria suggests an incidence of 55 per 1000 infants requiring phototherapy and 19 per 1000 infants requiring exchange blood transfusion [24]. Widespread glucose-6-phosphate dehydrogenase (G6PD) deficiency is also a principal predisposing factor to severe jaundice in Nigerian infants aggravated by $(\mathrm{TA})_{\mathrm{n}}$ promoter polymorphism of the uridinediphospate-glucuronosyltransferase 1A1 gene (UGT1A1) [25] and possibly the active promotion of exclusive breastfeeding [26]. Appropriate policy initiatives embracing maternal and health professional education, provision of functional phototherapy units and bilirubin monitoring devices are evidently warranted to prevent or significantly reduce the unrecognised contributions of jaundice to neonatal mortality in Nigeria as well as the related morbidity and disability among the survivors.

While tetanus remains as a significant cause of mortality, the overall ranking below jaundice may reflect both global and national progress in curtailing its incidence largely due to improved routine tetanus toxoid immunisation and greater awareness on the importance of clean cord care in hospitals and among primary health care workers including traditional birth attendants [1,27-30]. Nonetheless, concerns still persist on the unacceptably high levels of tetanus-related mortality in many locations which deserve urgent attention. Traditional uvulectomy is the suspected portal of entry in majority of cases followed by the unhealed umbilical cord. The traditional practice of cutting the uvula between the third and seventh days of life as well as unhygienic handling of the 
umbilical cord are major contributory factors to the high incidence of neonatal tetanus. Current global efforts aimed at promoting facility-based delivery or homedelivery attended by trained midwives as well as clean birth and postnatal practices as recommended by the World Health Organisation: and immunisation of pregnant women and those of childbearing age obviously need to be intensified at all levels of obstetric/perinatal care delivery.

It is not uncommon for the term "neonatal sepsis" to be collectively used for septicaemia, meningitis and pneumonia because of the challenge of diagnosing these infections accurately in many resource-poor settings and lack of uniform clinical criteria for their evaluation. This fact is worth noting in interpreting our results. As expected, the relative importance of congenital abnormalities as a cause of neonatal deaths diminishes as other largely preventable causes of death remain prominent in contrast to the pattern in countries with wellestablished healthcare systems. Notwithstanding, the disability associated with this condition was rated higher than the related mortality. The ranking for diarrhoea accurately suggests a far lesser burden among neonates compared with older infants and young children worldwide. For example, diarrhoea accounts for $18 \%$ of child deaths in Africa compared to $1 \%$ of neonatal deaths [1]. Birth trauma was most widely cited in the category of "other conditions" which perhaps reflects on the quality and challenges of obstetric care delivered in some hospitals especially at the secondary levels.

The lower ranking for birth asphyxia in relation to hospital admissions, mortality and morbidity among residents compared with consultants warrant further investigation. Similarly, it was unclear why residents compared with consultants ranked tetanus higher and sepsis lower in terms of mortality. The views of residents as first line physicians must be balanced by cumulative experience of consultants and professors in explaining the observed differences. The lack of differences between professors and consultants should be expected as the professors are themselves consultants in tertiary clinical settings with academic distinctions.

The major strengths of this study are its novelty as well as the geographical representativeness and working experience of respondents besides the prospect of facilitating a mutually-shared awareness between policy makers and paediatricians on the priorities for newborn health in this population. The response rate would also appear satisfactory considering prevailing challenges to web-based surveys especially among busy physicians in settings with limited internet connectivity. While the lack of comprehensive demographic data on those contacted precluded comparison of respondents and nonrespondents, a random interview of non-respondents for example, suggested that some individuals did not consider it necessary to participate once they ascertained that their colleagues more closely associated with neonatal care had responded resulting in some response bias. It was also not unlikely that some eligible respondents were not enlisted with PAN or were wrongly excluded during verification with potential for selection bias. Notwithstanding, the key findings accord with available literature from Africa on neonatal health and support calls to also pay attention to the optimal growth and development of the many survivors of these conditions as far as practicable. Perhaps more importantly, this study exemplifies a practical approach to overcoming the constraints of requisite data drought on some aspects of newborn health in resource-poor countries.

\section{Conclusion}

While current global priorities for neonatal survival in Nigeria are derived from limited published data the evidence from this survey suggests that they largely accord with paediatricians' views except for neonatal jaundice which is commonly subsumed under miscellaneous neonatal conditions. The need to recognise the importance of these priority conditions beyond mortality is also demonstrated. These findings should motivate paediatricians to play a more active role in advancing appropriate interventions to facilitate the attainment of current performance targets for newborn health in this population.

\section{Additional file}

Additional file 1: Survey on neonatal care in Nigeria.

This work has been presented at the 5 thScientific Conference of the Nigerian Society for Neonatal Medicine (NISONM), Lagos, Nigeria, June 27-29, 2012.

\section{Competing interests}

The authors declare that they have no competing interests.

\section{Authors' contributions}

BOO conceived and designed the study with critical inputs from EKA. BOO, EKA and CVE participated in data collection from Southwest Nigeria, GEO from Southeast Nigeria and MMY from Northern Nigeria. All authors contributed to the data analysis and the interpretation of the results. BOO drafted the manuscript. All other authors critically reviewed the draft, read and approved the final manuscript.

\section{Acknowledgements}

The authors are grateful to several colleagues who took time to participate in this survey and for the very helpful comments on the survey instrument by Tina Slusher (USA) and Professor Sam Olowe, Emeritus Professor of Paediatrics and Retired Consultant Neonatologist.

\section{Author details}

${ }^{1}$ Healthy Start Initiative, Ikoyi, Lagos, Nigeria. ${ }^{2}$ Department of Paediatrics, Lagos University Teaching Hospital, Surulere, Lagos, Nigeria. ${ }^{3}$ Department of Paediatrics, Lagoon Hospitals, Apapa, Lagos, Nigeria. ${ }^{4}$ Department of Paediatrics, National Hospital, Abuja, Nigeria. ${ }^{5}$ Department of Child Health, College of Medical Sciences, University of Benin, Benin City, Nigeria. 
Received: 14 November 2011 Accepted: 18 June 2012 Published: 2 July 2012

\section{References}

1. Black RE, Cousens S, Johnson HL, Lawn JE, Rudan I, Bassani DG, Jha P, Campbell H, Walker CF, Cibulskis R, Eisele T, Liu L, Mathers C, Child Health Epidemiology Reference Group of WHO and UNICEF: Global, regional, and national causes of child mortality in 2008: a systematic analysis. Lancet 2010, 375:1969-1987.

2. Lozano R, Wang H, Foreman KJ, Rajaratnam JK, Naghavi M, Marcus JR, Dwyer-Lindgren L, Lofgren KT, Phillips D, Atkinson C, Lopez AD, Murray CJ: Progress towards Millennium Development Goals 4 and 5 on maternal and child mortality: an updated systematic analysis. Lancet 2011, 378:1139-1165.

3. Lawn JE, Rudan I, Rubens C: Four million newborn deaths: is the global research agenda evidence-based? Early Hum Dev 2008, 84:809-814.

4. Commission on Social Determinants of Health (CSDH): Closing the gap in generation: health equity through action on the social determinants of health Final Report of the Commission on Social Determinants of Health. Geneva: World Health Organization; 2008.

5. The Young Infants Clinical Signs Study Group: Clinical signs that predict severe illness in children under age 2 months: a multicentre study. Lancet 2008, 371:135-142.

6. Committee on Nervous System Disorders in Developing Countries, Board on Global Health: Neurological, psychiatric and developmental disorders: meeting the challenge in the developing world. Washington D.C: National Academy Press; 2001.

7. VanGeest JB, Johnson TP, Welch VL: Methodologies for improving response rates in surveys of physicians: a systematic review. Eval Health Prof 2007, 30:303-321.

8. Cabana MD, Rand CS, Powe NR, Wu AW, Wilson MH, Abboud PA, Rubin HR: Why don't physicians follow clinical practice guidelines? A framework for improvement. JAMA 1999, 282:1458-1465.

9. English M, Ngama M, Musumba C, Wamola B, Bwika J, Mohammed S, Ahmed M, Mwarumba S, Ouma B, McHugh K, Newton C: Causes and outcome of young infant admissions to a Kenyan district hospital. Arch Dis Child 2003, 88:438-443.

10. Ogunlesi TA, Dedeke IO, Adekanmbi AF, Fetuga MB, Ogunfowora OB: The incidence and outcome of bilirubin encephalopathy in Nigeria: A bicentre study. Niger J Med 2007, 16:354-359.

11. Owa JA, Ogunlesi TA: Why we are still doing so many exchange blood transfusion for neonatal jaundice in Nigeria. World J Pediatr 2009, 5:51-55.

12. Nte AR, Yarhere I, Fiebai P: Paediatric mortality: a review of causes among admissions at the University of Port Harcourt Teaching Hospital (January 2003 - December 2005). Nig J Paediatr 2006, 33:90-98.

13. Ezeaka VC, Ogunbase OA, Awogbemi OT, Grange AO: Why our children die: A review of paediatric mortality in a tertiary centre in Lagos, Nigeria. Nig Q J Hosp Med 2003, 13:17-21.

14. Ahmed H, Yakubu AM, Hendrickse RG: Neonatal jaundice in Zaria, Nigeria-a second prospective study. West Afr J Med 1995, 14:15-23.

15. Slusher TM, Vreman HJ, McLaren DW, Lewison LJ, Brown AK, Stevenson DK: Glucose-6-phosphate dehydrogenase deficiency and carboxyhemoglobin concentrations associated with bilirubin-related morbidity and death in Nigerian infants. J Pediatr 1995, 126:102-108.

16. Fawole AO, Shah A, Tongo O, Dara K, El-Ladan AM, Umezulike AC, Alu FE, Eniayewun AB, Fabanwo AO, Adewunmi AA, Adegbola O, Adebayo AA, Obaitan FO, Onala OE, Usman Y, Sullayman AO, Kailani S, Sa'id M: Determinants of perinatal mortality in Nigeria. Int J Gynaecol Obstet 2011, 114:37-42.

17. Federal Ministry of Health. Saving newborn lives in Nigeria: Newborn health in the context of the Integrated Maternal, Newborn and Child Health Strategy. 2nd edition. Abuja: Federal Ministry of Health, Save the Children, Jhpiego; 2011.

18. Oestergaard MZ, Inoue M, Yoshida S, Mahanani WR, Gore FM, Cousens S, Lawn JE, Mathers CD, on behalf of the United Nations Inter-agency Group for Child Mortality Estimation and the Child Health Epidemiology Reference Group: Neonatal mortality levels for 193 countries in 2009 with trends since 1990: a systematic analysis of progress, projections, and priorities. PLoS Med 2011, 8:e1001080.
19. Tongo OO, Orimadegun AE, Ajayi SO, Akinyinka OO: The economic burden of preterm/very low birth weight care in Nigeria. J Trop Pediatr 2009, 55:262-264.

20. Bernstein J, Brown AK: Sepsis and jaundice in early infancy. Pediatrics 1962, 29:873-882.

21. Gordon AL, English M, Tumaini Dzombo J, Karisa M, Newton CR: Neurological and developmental outcome of neonatal jaundice and sepsis in rural Kenya. Trop Med Int Health 2005, 10:1114-1120.

22. Oyebola DDO: Care of the neonate and management of neonatal jaundice as practised by Yoruba traditional healers of Nigeria. $J$ Trop Pediatr 1983, 29:18-22.

23. Owa JA, Adebami OJ, Fadero FF, Slusher TM: Irradiance readings of phototherapy equipment: Nigeria. Indian J Pediatr 2011, 78:996-998.

24. Olusanya BO, Akande AA, Emokpae A, Olowe SA: Infants with severe neonatal jaundice in Lagos, Nigeria: prevalence, correlates and hearing screening outcomes. Trop Med Int Health 2009, 14:301-310.

25. Kaplan M, Slusher T, Renbaum P, Essiet DF, Pam S, Levy-Lahad E, Hammerman C: (TA)n UDP-glucuronosyltransferase 1A1 promoter polymorphism in Nigerian neonates. Pediatr Res 2008, 63:109-111.

26. Chang PF, Lin YC, Liu K, Yeh SJ, Ni YH: Risk of hyperbilirubinemia in breast-fed infants. J Pediatr 2011, 159:561-565.

27. Blencowe H, Cousens S, Mullany LC, Lee AC, Kerber K, Wall S, Darmstadt GL, Lawn JE: Clean birth and postnatal care practices to reduce neonatal deaths from sepsis and tetanus: a systematic review and Delphi estimation of mortality effect. BMC Publ Health 2011, 11(Suppl 3):S11.

28. Onalo R, Ishiaku HM, Ogala WN: Prevalence and outcome of neonatal tetanus in Zaria, Northwestern Nigeria. J Infect Dev Ctries 2011, 5:255-259.

29. Hassan B, Popoola A, Olokoba A, Salawu FK: A survey of neonatal tetanus at a district general hospital in north-east Nigeria. Trop Doct 2011, 41:18-20.

30. Fetuga BM, Ogunlesi TA, Adekanmbi FA: Risk factors for mortality in neonatal tetanus: a 15-year experience in Sagamu, Nigeria. World J Pediatr 2010, 6:71-75.

doi:10.1186/1472-698X-12-9

Cite this article as: Olusanya et al:: Paediatricians' perspectives on global health priorities for newborn care in a developing country: a national survey from Nigeria. BMC International Health and Human Rights 2012 12:9.

\section{Submit your next manuscript to BioMed Central and take full advantage of:}

- Convenient online submission

- Thorough peer review

- No space constraints or color figure charges

- Immediate publication on acceptance

- Inclusion in PubMed, CAS, Scopus and Google Scholar

- Research which is freely available for redistribution 